\title{
Desempenho e composição corporal de suínos alimentados com rações com baixos teores de proteína bruta
}

\author{
Vladimir de Oliveira(1), Elias Tadeu Fialho(2), José Augusto de Freitas Lima ${ }^{(2)}$, Rilke Tadeu Fonseca de Freitas(2), \\ Raimundo Vicente Sousa(2) e Antônio Gilberto Bertechini(2)
}

(1)Universidade Estadual do Oeste do Paraná, Centro de Ciências Agrárias, Campus de Mal. Cândido Rondon, Caixa Postal 1008, CEP 85960-000 Marechal Cândido Rondon, PR. E-mail: v_olliveira@yahoo.com.br (2)Universidade Federal de Lavras, Dep. de Zootecnia, Caixa Postal 3037, CEP37200-000 Lavras, MG.E-mail: fialho@ufla.br, jflima@ufla.br, rilke@ufla.br, rvsousa@ufla.br, agbertechini@ufla.br

\begin{abstract}
Resumo - O objetivo deste estudo foi avaliar o desempenho e composição corporal de suínos, alimentados com rações com baixos teores de proteína bruta, suplementadas com aminoácidos. Foram utilizados 38 suínos castrados em fase de crescimento, dos quais oito foram abatidos no início do experimento. Os trinta suínos restantes foram distribuídos em cinco tratamentos, com seis repetições em delineamento de blocos ao acaso. Os tratamentos foram rações com 10, 12, 14 e 16\% de proteína, e um tratamento com adição de nitrogênio de aminoácido não essencial na ração com 10\% de proteína. Os suínos alimentados com as rações 12, 14 e 16\% de proteína tiveram maior ganho de peso e melhor conversão alimentar. Ocorreu maior deposição de proteína na carcaça dos suínos que consumiram as rações 14 e 16\% de proteína. A deposição lipídica foi maior nos suínos alimentados com rações com $10 \%$ de proteína, e menor nos animais alimentados com ração com $16 \%$ de proteína. A redução do teor de proteína na ração de suínos até o teor de $12 \%$ não influencia o desempenho e a retenção de proteína, desde que as dietas sejam suplementadas com aminoácidos essenciais. Contudo, o decréscimo de proteína aumenta a gordura corporal.
\end{abstract}

Termos para indexação: nutrição animal, proteína ideal, deposição de proteína.

\section{Performance and body composition of swine fed low protein diets}

\begin{abstract}
The aim of this study was to evaluate the performance and the body composition of swine fed diets with low crude protein, but supplemented with amino acids. Thirty-eight young castrated swine were used, out of which eight were slaughtered in the beginning of the experiment. The remaining 30 swine were allotted in five treatments and six replications using a randomized block experimental design. The treatments consisted of rations with $10,12,14$ and $16 \%$ protein, and a treatment of ration with $10 \%$ protein supplemented with nitrogen from a nonessential amino acid source. Swine fed with rations 12, 14 and 16\% protein had greater daily gain and better feed conversion. The protein deposition was bigger in swine feeding rations 16 and 14\%, in comparison to those fed rations with $10 \%$ protein. The rate of lipid deposition was lower in swine fed on ration with $16 \%$ protein, and higher in swine fed ration with $10 \%$ protein. The crude protein reduction levels of the ration until $12 \%$ limit do not influence the performance and the retention of protein in swine, since diets are supplemented with essential amino acids. However, the protein level decrease of the ration increases body fat.
\end{abstract}

Index terms: animal nutrition, ideal protein, protein deposition.

\section{Introdução}

As dietas fornecidas aos suínos contêm alta concentração de proteína, para evitar deficiências de aminoácidos e garantir o máximo desempenho. O excesso protéico nas dietas eleva a quantidade de nitrogênio que é eliminado nas fezes e urina e ocasiona problemas ambientais (National Research Council, 1998).
Uma das estratégias recomendadas para diminuir o conteúdo de nitrogênio nos dejetos e o impacto ambiental da suinocultura é a redução do teor de proteína bruta das rações (Le Bellego et al., 2001; Kerr et al., 2003). Por meio da análise dos resultados de vários estudos, pode-se afirmar que dietas com baixa proteína reduzem o nitrogênio excretado e podem propiciar retenção de nitrogênio similar à obtida com ração convencional, desde 
que os aminoácidos essenciais sejam suplementados, para evitar deficiências nutricionais (Noblet et al., 2001; Kerr et al., 2003). Contudo, em muitos dos experimentos realizados para testar rações com baixos teores de proteína bruta, o menor nível protéico avaliado esteve próximo de 14\% (Gatel \& Grosjean, 1992; Tuitoek et al., 1997). É possível que isso ocorra, porque a redução acentuada da concentração protéica implica na necessidade de inclusão de outros aminoácidos sintéticos além da lisina, treonina, metionina e triptofano, como por exemplo a valina e a isoleucina (Le Bellego \& Noblet, 2002).

Nos experimentos de Noblet et al. (2001), em que a redução do teor de proteína da dieta foi acentuada, também ocorreu decréscimo linear na excreção de nitrogênio. Entretanto, alguns autores têm demonstrado que rações com aproximadamente $12 \%$ de proteína na dieta resultam em menor retenção de nitrogênio (Figueroa et al., 2002).

Além disso, tem-se verificado que suínos depositam maior quantidade de gordura na carcaça, quando são alimentados com rações com baixos teores de proteína bruta (Moehn \& Susenbeth, 1995). Tais respostas estão associadas ao conteúdo de energia líquida das rações, que é inversamente proporcional à concentração de proteína (Noblet et al., 1987).

Sabe-se, assim, que a redução do teor de proteína é uma alternativa para amenizar o impacto ambiental da suinocultura. Contudo, os efeitos destas rações no crescimento dos animais não estão totalmente esclarecidos.

O objetivo deste estudo foi avaliar o desempenho e a composição corporal de suínos, em fase de crescimento, alimentados com dietas com diferentes teores de proteína bruta.

\section{Material e Métodos}

O experimento foi realizado no setor de suinocultura, do Departamento de Zootecnia, da Universidade Federal de Lavras. Foram utilizados 38 suínos ( $32 \pm 1,05 \mathrm{~kg}$ ) machos castrados, mestiços e de alto potencial para deposição de carne magra. Um grupo de oito animais foi abatido, no início do experimento, para se determinar a composição química inicial, e serviram como controle para o cálculo das taxas de deposição de proteína e lipídeos. Os 30 suínos restantes foram alojados individualmente e divididos em cinco tratamentos, com seis repetições, por meio do delineamento de blocos ao acaso, cujo critério para formação dos blocos foi o peso inicial.
Os tratamentos consistiram de rações isoenergéticas e isolisínicas, formuladas para possuir 10, 12, 14 e 16\% de proteína bruta (Tabela 1), e de um tratamento ao qual se adicionou uma mistura de nitrogênio de aminoácido não essencial (NNE), na ração com 10\% de proteína $(10+\mathrm{NNE})$. Como fonte de NNE, foi adicionada uma mistura de ácido glutâmico, glicina e prolina, na proporção 60:30:10 (Chung \& Baker, 1991; Heger et al., 1998). A composição química e os coeficientes de digestibilidade ileal verdadeira, dos aminoácidos contidos nos ingredientes, foram obtidos no National Research Council (1998). A quantidade de ração fornecida diariamente foi de 3,5 vezes a energia de manutenção, calculada como $106 \mathrm{kcal}$ de EM por quilograma de $\mathrm{PV}^{0,75}$, adequada para animais mantidos em ambiente termoneutro (National Research Council, 1998). Os animais foram pesados individualmente, duas vezes por semana, para estabelecer a quantidade de ração a ser fornecida. A água esteve disponível para consumo à vontade.

Ao término do experimento, os suínos foram sacrificados após jejum de aproximadamente 14 horas. No momento do abate, os animais foram dessensibilizados e procedeu-se à sangria, tendo-se colhido e quantificado o sangue. $\mathrm{O}$ trato gastrintestinal, vísceras abdominais e torácicas, ligamentos, gordura interna, cabeça, pés e cauda foram retirados da carcaça e pesados.

A carcaça foi longitudinalmente dividida ao meio, e a metade esquerda foi resfriada por um período de 24 horas. Posteriormente, as carcaças (sem cabeça, pés e cauda) foram divididas em pequenos cubos, acondicionadas em sacos de plástico e armazenadas em congelador $\left(-20^{\circ} \mathrm{C}\right)$. Carcaças e vísceras foram moídas três vezes em peneira com tela de $2 \mathrm{~mm}$, antes de se retirar uma amostra homogênea por animal. A seguir, as amostras foram encaminhadas para processamento e análises laboratoriais.

Para a determinação da matéria seca, amostras dos ingredientes, rações, carcaça e vísceras foram mantidas em estufa, a $65^{\circ} \mathrm{C}$, até se obter massa constante, e foram, posteriormente, colocadas em estufa a $105^{\circ} \mathrm{C}$, por 24 horas. Os conteúdos de nitrogênio descritos foram determinados pelo método de Kjeldahl (Association of Official Analytical Chemists, 1990). As concentrações de extrato etéreo e cinzas foram determinadas com metodologias descritas por Silva \& Queiroz (2002). A fibra em detergente ácido e a fibra em detergente neutro foram analisadas com uso de metodologia descrita 
por Van Soest \& Wine (1967). A energia bruta foi quantificada com auxílio de bomba calorimétrica adiabática.

Quando o teste F da análise de variância foi significativo para o efeito de tratamento, a diferença entre tratamentos foi avaliada pelo teste t múltiplo, tendo-se utilizado a opção LSD do SAS (Saville, 1990; Tuitoek et al., 1997; Le Bellego et al., 2001). O peso de abate foi usado como covariável nas variáveis: retenção de proteína e lipídeos. Considerou-se que houve significância estatística, sempre que a probabilidade de cometer o erro tipo I foi inferior a 0,05 . As análises estatísticas foram realizadas com o PROC GLM do SAS (SAS Institute, 2000).

\section{Resultados e Discussão}

Os resultados das variáveis de desempenho são mostrados na Tabela 2. O peso final dos suínos foi semelhante, independentemente do tratamento experimental. Houve diferenças no tempo necessário para atingirem o peso de abate. Os suínos alimentados com as rações com 12, 14 e 16\% de proteína atingiram o peso de abate, em média, três a cinco dias mais cedo do que os animais da ração 10+NNE e 10, respectivamente.

Os suínos alimentados com as rações 12, 14 e 16\% de proteína apresentaram ganho de peso médio 16\% superior aos animais que consumiram as rações $10+$ NNE

Tabela 1. Composição porcentual das rações experimentais utilizadas.

\begin{tabular}{|c|c|c|c|c|c|}
\hline \multirow[t]{2}{*}{ Ingrediente $(\%)$} & \multicolumn{5}{|c|}{ Rações experimentais } \\
\hline & $10+\mathrm{NNE}$ & 10 & 12 & 14 & 16 \\
\hline Milho & 52,375 & 54,175 & 75,630 & 84,395 & 78,670 \\
\hline Amido & 34,00 & 34,00 & 11,52 & - & - \\
\hline Farelo de soja & 7,00 & 6,60 & 8,50 & 11,75 & 18,00 \\
\hline Fosfato bicálcico & 1,50 & 1,50 & 1,50 & 1,50 & 1,50 \\
\hline Calcário calcítico & 0,90 & 0,90 & 0,90 & 0,90 & 0,90 \\
\hline Sal & 0,40 & 0,40 & 0,40 & 0,40 & 0,40 \\
\hline Suplemento vitamínico ${ }^{(1)}$ & 0,10 & 0,10 & 0,10 & 0,10 & 0,10 \\
\hline Suplemento mineral ${ }^{(2)}$ & 0,10 & 0,10 & 0,10 & 0,10 & 0,10 \\
\hline L-Lisina $\mathrm{HCl}$ & 0,71 & 0,71 & 0,58 & 0,45 & 0,24 \\
\hline L-Treonina & 0,35 & 0,35 & 0,26 & 0,18 & 0,08 \\
\hline L-Triptofano & 0,10 & 0,10 & 0,08 & 0,05 & 0,01 \\
\hline DL-Metionina & 0,14 & 0,14 & 0,09 & 0,06 & - \\
\hline L-Valina & 0,26 & 0,26 & 0,14 & 0,045 & - \\
\hline L-Isoleucina & 0,25 & 0,25 & 0,15 & 0,07 & - \\
\hline L-Leucina & 0,14 & 0,14 & - & - & - \\
\hline L-Fenilalanina & 0,19 & 0,19 & 0,05 & - & - \\
\hline L-Histidina & 0,085 & 0,085 & - & - & - \\
\hline L-Ácido glutâmico & 1,00 & - & - & - & - \\
\hline Glicina & 0,30 & - & - & - & - \\
\hline \multirow[t]{2}{*}{ Prolina } & 0,10 & - & - & - & - \\
\hline & \multicolumn{5}{|c|}{ Composição das rações experimentais } \\
\hline Energia metabolizável $\left(\mathrm{kcal} \mathrm{kg}^{-1}\right)$ & 3.291 & 3.292 & 3.291 & 3.290 & 3.300 \\
\hline Proteína bruta $(\%)$ & 10,95 & 9,73 & 12,26 & 14,30 & 16,22 \\
\hline Fósforo disponível (\%) & 0,310 & 0,310 & 0,321 & 0,330 & 0,338 \\
\hline Cálcio $(\%)$ & 0,741 & 0,740 & 0,746 & 0,758 & 0,779 \\
\hline Lisina digestível verdadeira (\%) & 0,845 & 0,846 & 0,831 & 0,837 & 0,833 \\
\hline $\mathrm{NE}: \mathrm{NT}$ & 0,40 & 0,45 & 0,36 & 0,31 & 0,27 \\
\hline
\end{tabular}

(1)Suplemento vitamínico (por kg de produto): vitamina A (8.000.000 UI), vitamina $\mathrm{D}_{3}$ (1.200.000 UI), vitamina E (20.000 mg), vitamina $\mathrm{K}_{3}$ $(2.500 \mathrm{mg})$, tiamina $(1.000 \mathrm{mg})$, riboflavina $(4.000 \mathrm{mg})$, piridoxina $(2.000 \mathrm{mg})$, niacina $(25.000 \mathrm{mg})$, ácido pantotênico (10.000 mg), ácido fólico (600 mg), biotina (50 mg), vitamina C (50.000 mg), antioxidante (125 mg), antibiótico (15.000 mg). ${ }^{(2)}$ Suplemento mineral (por kg de produto): Cu (20.000 mg), I (800 mg), Mn (40.000 mg), Se (156 mg), Zn (80.000 mg), Fe (70.000 mg), Co (500 mg).

Tabela 2. Teor de proteína e suplementação de aminoácidos não essenciais (NNE) no desempenho de suínos em crescimento(1).

\begin{tabular}{|c|c|c|c|c|c|c|}
\hline \multirow[t]{2}{*}{ Variável } & \multicolumn{5}{|c|}{ Rações experimentais } & \multirow[t]{2}{*}{$\mathrm{EPM}^{(2)}$} \\
\hline & $10+\mathrm{NNE}$ & 10 & 12 & 14 & 16 & \\
\hline Peso inicial $(\mathrm{kg})$ & 32,9 & 33,3 & 33,3 & 33,4 & 33,2 & 0,28 \\
\hline Peso final $(\mathrm{kg})$ & 56,1 & 56,9 & 57,4 & 56,2 & 56,6 & 0,52 \\
\hline Tempo para atingir peso de abate (dias) & $30,0 \mathrm{ab}$ & $32,0 \mathrm{a}$ & $27,4 b c$ & $26,6 \mathrm{c}$ & $26,9 \mathrm{c}$ & 0,70 \\
\hline Consumo médio e ração $(\mathrm{g})$ & 1.891 & 1.907 & 1.895 & 1.896 & 1.894 & 89,01 \\
\hline Ganho médio de peso $(\mathrm{g})$ & $764 b$ & $740 \mathrm{~b}$ & $878 \mathrm{a}$ & $865 \mathrm{a}$ & $867 \mathrm{a}$ & 19,08 \\
\hline Conversão alimentar & $2,48 \mathrm{a}$ & $2,58 \mathrm{a}$ & $2,15 b$ & $2,20 \mathrm{~b}$ & $2,19 b$ & 0,05 \\
\hline
\end{tabular}

${ }^{(1)}$ Médias seguidas de letras iguais, na mesma linha, não diferem entre si pelo teste t múltiplo $(\mathrm{p}<0,05)$. ${ }^{(2)}$ Erro-padrão da média. 
e 10\% de proteína. Estes resultados não eram esperados, pois as rações foram isonutritivas e o consumo alimentar não se diferenciou entre os tratamentos. Contudo, Otto et al. (2003) forneceram rações com 10,2\% de proteína, formuladas com base no conceito de proteína ideal, e também verificaram que estas rações limitam o desempenho de suínos em crescimento.

As causas que provocaram a redução do ganho de peso, nos suínos alimentados com as rações com 10+NNE e 10\% de proteína, não estão claras, contudo algumas explicações podem ser discutidas. Existem vários estudos que demonstram que aminoácidos sintéticos são absorvidos mais rapidamente do que aqueles que estão ligados às proteínas dos alimentos, o que resulta no desequilíbrio de aminoácidos em nível celular (Officer et al., 1997). Além disso, tem sido comprovado que rações com baixa proteína, suplementadas com aminoácidos sintéticos, propiciam a redução no desempenho, porque alteram bioquímica e morfologicamente a mucosa do intestino delgado (Guay et al., 2006).

A conversão alimentar foi melhor nos suínos alimentados com as rações 12, 14 e 16, em comparação aos suínos das rações 10+NNE e 10\%, embora dentro desses grupos não tenham ocorrido diferenças. No presente experimento, as diferenças na conversão alimentar podem estar associadas à composição do ganho de peso, pois quando o acúmulo de peso ocorre, predominantemente, na forma de gordura, registra-se piora na conversão alimentar (Wenk et al., 1980).

O peso de abate, peso de carcaça, peso dos órgãos, incluindo-se cabeça, pés, cauda e sangue, peso corporal vazio, e a composição química média, dos animais abatidos no início do experimento, estão apresentados na Tabela 3. Todos os resultados estão dentro de valores encontrados em outro experimento, que utilizou suínos

Tabela 3. Peso de abate, peso das frações corporais e composição química das frações carcaça, órgãos e corpo vazio, dos suínos abatidos no início do experimento.

\begin{tabular}{lrc}
\hline Variável & Total & EPM $^{(1)}$ \\
\hline Peso de abate $(\mathrm{kg})$ & 30,70 & 0,36 \\
Peso da carcaça $^{(2)}(\mathrm{kg})$ & 20,50 & 0,27 \\
Peso dos órgãos $^{(3)}(\mathrm{kg})$ & 8,10 & 0,21 \\
Peso corporal vazio $^{(4)}(\mathrm{kg})$ & 28,60 & 0,29 \\
\hline Composição do corpo vazio & & \\
$\quad$ Umidade (\%) & 66,80 & 0,24 \\
$\quad$ Proteína (\%) & 17,40 & 0,17 \\
$\quad$ Lipídeos $(\%)$ & 12,78 & 0,24 \\
Cinzas $(\%)$ & 2,77 & 0,02 \\
\hline
\end{tabular}

(1)Erro-padrão da média. (2)Peso da carcaça sem cabeça, pés e cauda. (3)Peso dos órgãos viscerais, cabeça, pés, cauda e sangue. (4)Equivalente aos pesos: da carcaça, órgãos viscerais, cabeça, pés, cauda e sangue. com peso semelhante ao deste trabalho (Gómez et al., 2002).

Os resultados de composição química, deposição de proteína e gordura no corpo vazio estão apresentados na Tabela 4. O teor de umidade do corpo vazio foi influenciado pelos tratamentos. Os suínos da ração com 16\% de proteína foram os que tiveram maiores teores de umidade, embora não tenham diferido dos suínos alimentados com a ração com 14\% de proteína. Os animais da ração com $10 \%$ de proteína apresentaram os menores teores de umidade no corpo vazio. O teor de umidade médio dos suínos, submetidos ao tratamento $10+\mathrm{NNE}$, foi intermediário entre os tratamentos com 16 e 10\% de proteína, mas não diferiu dos animais das rações com 12 e 14\% de proteína.

A concentração de proteína corporal dos suínos não foi influenciada pelos tratamentos. O valor médio encontrado neste experimento foi de aproximadamente $15,5 \%$, muito semelhante aos valores médios da literatura (Tuitoek et al., 1997; Le Bellego \& Noblet, 2002; Kerr et al., 2003). Na maior parte dos trabalhos consultados, verifica-se que o consumo de proteína não altera a concentração protéica da carcaça (Tuitoek et al., 1997; Gómez et al., 2002; Le Bellego \& Noblet, 2002), embora haja exceções (Kerr et al., 2003).

As rações experimentais influenciaram a concentração de lipídeos no corpo vazio dos suínos, embora o valor médio tenha sido semelhante ao obtido por outros autores (Gómez et al., 2002; Kerr et al., 2003). Os animais alimentados com a ração com $10 \%$ de proteína tiveram maior quantidade de lipídeos no corpo vazio que os demais grupos. A menor concentração de gordura foi observada nos animais alimentados com a ração de 16\% de proteína. Suínos alimentados com as rações $10+\mathrm{NNE}, 12$ e $14 \%$ de proteína apresentaram valores intermediários e semelhantes.

Tabela 4. Composição química, deposição de proteína (DP) e deposição de lipídeos (DLIP), no corpo vazio de suínos alimentados com rações com diferentes concentrações de proteína bruta e com suplementação de aminoácidos não essenciais $^{(1)}$.

\begin{tabular}{lllllll}
\hline Variável & \multicolumn{5}{c}{ Rações experimentais } & \multirow{2}{*}{ EPM $^{(2)}$} \\
\cline { 2 - 5 } & $10+\mathrm{NNE}$ & 10 & 12 & 14 & 16 & \\
\hline Umidade (\%) & $63,00 \mathrm{~b}$ & $61,55 \mathrm{c}$ & $63,98 \mathrm{bc}$ & $63,88 \mathrm{ab}$ & $64,36 \mathrm{a}$ & 0,36 \\
Proteína (\%) & 15,23 & 15,37 & 15,66 & 15,50 & 15,75 & 0,20 \\
Lipídeos (\%) & $18,55 \mathrm{~b}$ & $19,98 \mathrm{a}$ & $17,06 \mathrm{~b}$ & $17,30 \mathrm{~b}$ & $16,50 \mathrm{c}$ & 0,41 \\
DP $\left(\mathrm{g} \mathrm{d}^{-1}\right)$ & $99,83 \mathrm{~b}$ & $99,33 \mathrm{~b}$ & $111,67 \mathrm{ab}$ & $114,80 \mathrm{a}$ & $116,50 \mathrm{a}$ & 4,10 \\
DLIP $\left(\mathrm{g} \mathrm{d}^{-1}\right)$ & $193,17 \mathrm{ab}$ & $206,17 \mathrm{a}$ & $192,50 \mathrm{ab}$ & $192,17 \mathrm{ab}$ & $170,33 \mathrm{~b}$ & 9,20 \\
\hline
\end{tabular}

(1)Médias seguidas de letras iguais, na mesma linha, não diferem entre si pelo teste $t$ múltiplo $(\mathrm{p}<0,05)$. ${ }^{(2)}$ Erro-padrão da média. 
Não houve diferenças entre os tratamentos no conteúdo de cinzas do corpo vazio. Os valores obtidos estão dentro da amplitude encontrada em outros estudos (Tuitoek et al., 1997; Le Bellego \& Noblet, 2002).

Ocorreu efeito dos tratamentos na retenção de proteína corporal. A retenção de proteína foi maior nos suínos que consumiram as rações com 14 e 16\% de proteína, em comparação aos animais que ingeriram as rações com $10+$ NNE e $10 \%$ de proteína. Tais resultados ocorreram em razão da maior taxa de crescimento, observada nos animais alimentados com as rações 14 e 16\% de proteína, uma vez que não houve diferenças, entre os tratamentos, na porcentagem de proteína depositada no corpo vazio. Gómez et al. (2002) também verificaram maior retenção de proteína, em suínos que consumiram rações com 15,9\% de proteína, em relação àqueles alimentados com rações com 12,3\% de proteína, mesmo quando houve inclusão de aminoácidos sintéticos.

O valor médio de deposição de proteína, verificado neste experimento, foi cerca de 10 e $5 \%$ inferiores aos apresentados por Tuitoek et al. (1997) e Gómez et al. (2002), que trabalharam com fêmeas e suínos castrados, respectivamente. Inúmeros fatores interferem na taxa de deposição protéica de suínos como sexo, genótipo e o regime alimentar, o que contribui para as variações observadas entre experimentos.

A deposição de lipídeos foi influenciada pelas rações experimentais, mas seus valores estão dentro dos limites encontrados na literatura (Tuitoek et al., 1997; Gómez et al., 2002). A taxa de deposição de lipídeos foi menor nos animais alimentados com a ração com $16 \%$ de proteína, e foi maior nos animais que receberam rações com $10 \%$ de proteína. Os tratamentos 10+NNE, 12 e $14 \%$ de proteína foram semelhantes aos demais. Rações de baixa proteína causam maior deposição de gordura em suínos (Noblet et al., 1987; Le Bellego et al., 2001). Isso ocorre porque a redução do excesso de aminoácidos aumenta o conteúdo de energia disponível, em razão do menor gasto energético para catabolismo e excreção do excesso de nitrogênio da ração (Le Bellego et al., 2001). Outro argumento é que rações com menor quantidade de proteína influenciam no peso dos órgãos metabolicamente ativos. Há uma relação positiva entre gasto de energia e peso de órgãos metabolicamente ativos (Koong et al., 1983). Apesar de os órgãos metabolicamente ativos representarem menos de $10 \%$ do peso corporal, eles são responsáveis por uma parcela significativa das exigências de manutenção (Noblet et al., 1987). Também é preciso destacar que a redução do teor de proteína foi realizada com a substituição do farelo de soja por amido. Noblet et al. (1994) e Milgen et al. (2001) demonstraram que a energia metabolizável do amido é utilizada com maior eficiência que a energia da proteína (0,84 e 0,52, respectivamente).

\section{Conclusões}

1. A redução do teor de proteína bruta, da ração de suínos em crescimento, até o limite de $12 \%$, não altera o desempenho e a retenção de proteína, desde que as dietas sejam suplementadas com aminoácidos essenciais.

2. O decréscimo de proteína da ração aumenta a concentração de gordura corporal.

\section{Referências}

ASSOCIATION OF OFFICIAL ANALYTICAL CHEMISTS (Arlington, Estados Unidos). Official methods of analysis. $15^{\text {th }}$ ed. Arlington, 1990. 1230p.

CHUNG, T.K.; BAKER, D.H. A chemically defined diet for maximal growth of pigs. Journal of Nutrition, v.121, p.979-984, 1991.

FIGUEROA, J.L.; LEWIS, A.J.; MILLER, P.S.; FISCHER, R.L.; GÓMEZ, R.S.; DIEDRICHSEN, R.M. Nitrogen metabolism and growth performance of gilts fed standard corn-soybean meal diets or low-crude protein, amino acid-supplemented diets. Journal of Animal Science, v.80, p.2911-2919, 2002.

GATEL, F.; GROSJEAN, F. Effect of protein content of the diet on nitrogen excretion by pigs. Livestock Production Science, v.31, p.109-120, 1992.

GÓMEZ, R.S.; LEWIS, A.J.; MILLER, P.S.; CHEN, H.Y. Growth performance, diet apparent digestibility, and plasma metabolite concentrations of barrows fed corn-soybean meal diets or lowprotein, amino acid-supplemented diets at different feeding levels. Journal of Animal Science, v.80, p.644-653, 2002.

GUAY, F.; DONOVAN, S.M.; TROTTIER, N.L. Biochemical and morphological developments are partially impaired in intestinal mucosa from growing pigs fed reduced-protein diets supplemented with crystalline amino acids. Journal of Animal Science, v.84, p.1749-1760, 2006.

HEGER, J.; MENGESHA, S.; VODEHNAL, D. Effect of essential: total nitrogen ratio on protein utilization in the growing pigs. British Journal of Nutrition, v.80, p.537-544, 1998.

KERR, B.J.; SOUTHERN, L.L.; BIDNER, T.D.; FRIESEN, K.G.; EASTER, R.A. Influence of dietary protein level, amino acid supplementation, and dietary energy levels on growing-finishing pig performance and carcass composition. Journal of Animal Science, v.81, p.3075-3087, 2003.

KOONG, L.J.; NIENABER, J.A.; MERSMANN, H. Effects of plane of nutrition on organ size and fasting heat production in genetically obese and lean pigs. Journal of Nutrition, v.113, p.16261631, 1983. 
LE BELLEGO, L.; MILGEN, J. van; DUBOIS, S.; NOBLET, J. Energy utilization of low-protein diets in growing pigs. Journal of Animal Science, v.79, p.1259-1271, 2001.

LE BELLEGO, L.; NOBLET, J. Peformance and utilization of dietary energy and amino acids in piglets fed low protein diets. Livestock Production Science, v.76, p.45-58, 2002.

MILGEN, J. van; NOBLET, J.; DUBOIS, S. Energetic efficiency of starch, protein and lipid utilization in growing pigs. Journal of Nutrition, v.131, p.1309-1318, 2001.

MOEHN, S.; SUSENBETH, A. Influence of dietary protein content of efficiency of energy utilization in growing pigs. Archiv für Tierernährung, v.47, p.361-372, 1995.

NATIONAL RESEARCH COUNCIL (Washington, Estados Unidos). Nutrients requirements of swine. $10^{\text {th }} \mathrm{ed}$. Washington: National Academy of Sciences, 1998. 212p.

NOBLET, J.; FORTUNE, H.; SHI, X.S.; DUBOIS, S. Prediction of net energy value of feeds for growing pigs. Journal of Animal Science, v.72, p.344-354, 1994.

NOBLET, J.; HENRY, Y.; DUBOIS, S. Effect of protein and lysine levels in the diet on body gain composition and energy utilization in growing pig. Journal of Animal Science, v.65, p.717-726, 1987.

NOBLET, J.; LE BELLEGO, L.; MILGEN, J. van; DUBOIS, S. Effects of reduced dietary protein level and fat addition on heat production and nitrogen and energy balance in growing pigs. Animal Research, v.50, p.227-238, 2001.
OFFICER, D.I.; BATTERHAM, E.S.; FARREL, D.J. Comparison of growth performance and nutrient retention of weaner pigs given diets based on casein, free amino acids or conventional protein. British Journal of Nutrition, v.77, p.731-744, 1997.

OTTO, E.R.; YOKORAMA, M.; KU, P.K.; AMES, N.K.; TROTTIER, N.L. Nitrogen balance and ileal amino acid digestibility in growing pigs fed diets reduced in protein concentration. Journal of Animal Science, v.81, p.1743-1753, 2003.

SAS INSTITUTE (Cary, Estados Unidos). SAS: user's guide. Cary, 2000. 496p.

SAVILLE, D.J. Multiple comparison procedures: the practical solution. American Statistician, v.44, p.174-180, 1990.

SILVA, D.J.; QUEIROZ, A.C. Análises de alimentos: métodos químicos e biológicos. Viçosa: UFV, 2002. 235p.

TUITOEK, J.K.; YOUNG, L.G.; LANGE, C.F. de; KERR, B.J. Body composition and protein and fat accretion in various body components in growing gilts fed diets with different protein levels but estimated to contain similar levels of ideal protein. Journal of Animal Science, v.75, p.1584-1590, 1997.

VAN SOEST, P.J.; WINE, R.H. Use of detergents in the analysis of fibrous feeds. 4. Determination of plant cell-wall constituents. Journal of the Association of Official Analytical Chemists, v.50, p.50-55, 1967.

WENK, C.; PFIRTER, H.P.; BICKEL, H. Energetic aspects of feed conversion in growing pigs. Livestock Production Science, v.7, p.483-495, 1980.

Recebido em 9 de março de 2006 e aprovado em 25 de agosto de 2006 